\title{
OBITUARY
}

\section{DR. BENJAMIN H. KEAN, M.D.}

Ben Kean was an enthusiastic supporter of tropical medicine and a pioneer in the discipline of tropical infectious disease. In 1964 in the powerful Department of Infectious Disease at Cornell Medical School in New York Hospital he founded a small unit of tropical medicine. Its emphasis was on toxoplasmosis and schistosomiasis, two of his major interests, although he had previously made important contributions in the field of amoebiasis and diarrhoeal disease remained a life long interest. Today the Division of International Medicine with Dr. Warren Johnson as Kean professor is his worthy memorial. This division continues to have close associations with Brazil.

The writers met in Kean's department and participated in his famous course in tropical medidine which has stimulated many colleagues who were students at Cornell. He was an outstanding teacher and his lecturers were not only memorable they were fun. He himself was stimulated by Francis W. O'Connor when he took his course at Columbia University. He never forgot this debt. In the same way in his autobiography Kean remembered the details of the filtration technique to remove adult schistosomes from the portal tract whereas acknowledged Brazilian collaboration. After tropical experience as a pathologist in Panama he served in the American Military during the Second World War.

An outstanding contribution from his department is the two volumes of Classic Investigations in Tropical Medicine and Parasitology published by Cornell University Press in 1978. Intertest is growing in America in tropical infectious disease due to immigration, travel and a shrinking world. His advice will be missed. 